\section{Apically extruded debris in filling removal of curved canals using 3 NiTi systems and hand files}

Débora Delai, Daiana Boijink, Carolina Bender Hoppe, Fabiana Soares Grecca, Patrícia Maria Poli Kopper
'Dentistry Graduate Program, UFRGS - Univerdade Federal do Rio Grande do Sul, Porto Alegre, RS, Brazil

Correspondence: Patrícia Maria Poli, Kopper, Rua Ramiro Barcelos, 2492 CEP: 90035-003. Tel: +55-51-33085191 e-mail: pkopper@terra.com.br

\begin{abstract}
The aim of this study was to assess the amount of apically extruded debris during filling removal with WaveOne Gold (WOG), ProTaper Universal Retreatment (PTR), D-RaCe Retreatment (DRR) or hand files (HF), to compare the working time during filling removal, and to describe failures of NiTi instruments. Forty mesiobuccal roots of maxillary first molars were prepared with WOG Primary, obturated and divided into 4 groups $(n=10)$, according to the instruments used: WOG, PTR, DRR or HF. Distilled water was used as irrigant and the extruded debris were collected in Eppendorf tubes and dried. The amount of extruded debris was determined by subtracting the final from the initial weight. The time of filling removal for each canal was recorded and the instruments used were analyzed pre and post-operatively by SEM. Kruskal-Wallis and Dunn's test analyzed extruded debris data and ANOVA, followed by Tukey's test, compared the working time data $(\alpha=0.05)$. Instrument deformation and fracture were described. WOG produced significantly less debris compared with HF and DRR ( $p<0.05)$, and similar to PTR $(p>0.05)$. HF, PTR and DRR showed no significant difference ( $p>0.05)$. Working time in HF group was significantly higher than others $(p<0.05)$. SEM analyses showed, from the 18 instruments evaluated, 3 fractures and 10 deformations. All instruments tested caused debris extrusion. WOG was associated with less extrusion than DRR and HF. Filling removal with HF was slower than with the other instruments. All NiTi systems presented fracture and deformation.
\end{abstract}

Key Words: apical extrusion, debris, instrumentation, reciprocating movement, single-file systems.

\section{Introduction}

Cases of unresolved post-treatment periapical radiolucency are referred to as "endodontic failures" (1). Even when the highest standards of canal disinfection and filling are met, failures can occur because of the anatomical complexity of the root canal system (2). The majority of narrow root canals show some degree of curvature, which makes the retreatment procedures more challenging and may also cause procedural errors (3).

Endodontic retreatment requires total filling removal to enable the subsequent root canal instrumentation and disinfection (4). However, it is known that filling removal can lead to extrusion of debris and cause periapical inflammation, flare-ups or failure of apical healing (5). Different amounts of extruded debris have been reported, depending on the instrumentation technique and the design of instruments (5-12).

To quantify debris extrusion into periapical tissues during endodontic treatment, different laboratory experimental set-ups have been designed. The system that has been adopted by most studies was described by Myers and Montgomery (13), which consists of a rubber stopper, a glass vial and a flask made of glass. The assembly where the tooth is placed should be secured to prevent movement, and the flask should be shielded using a rubber dam so that the operator is not able to see the debris, simulating a clinical working environment (14).

The WaveOne single-file reciprocating system (WO, Dentsply Maillefer) has been introduced with a special nickel-titanium (NiTi) alloy (M-wire) presenting advantages as increased flexibility, improved resistance to cyclic fatigue, and minimal canal transportation (15-17). When used to filling removal, it has been reported as more effective when compared to rotational and hand files (18). WaveOne Gold system (WOG, Dentsply Maillefer), which was released in recent years, uses the same reciprocation action of WO but has modified dimensions and geometry. The files are manufactured using a manual gold heat treatment by heating the file and cooling slowly, providing a gold color to the instrument and improvement of 80\% in flexibility, 50\% in the resistance to cyclic fatigue, and 23\% in efficiency (19).

To date, some studies have evaluated apical debris extrusion when a single-file reciprocating system was used for filling removal $(8,10-12,18,20,21)$. However, few studies have evaluated the debris extrusion during endodontic retreatment in curved canals (11), and there are no studies regarding the performance of WOG in filling removal, neither in debris extrusion during filling removal of well-filled curved canals. 
Thus, the aim of this study was to evaluate the apically extruded debris, during filling removal, with WOG in comparison with ProTaper Universal Retreatment (PTR, Dentsply Maillefer), D-RaCe Retreatment (DRR, FKG Dentaire) and hand files (HF, Dentsply Maillefer), to compare the working time, and to describe failures of the NiTi instruments.

\section{Material and Methods}

This study was approved by the Institutional Review Board (CAAE 51687215.3.0000.5347).

\section{Sample Selection}

Forty human maxillary first molars with mature apex were selected, cleaned, disinfected and stored in distilled water at $4{ }^{\circ} \mathrm{C}$ until the experimental procedures. The mesiobuccal roots were isolated by sectioning the teeth twice, in buccal and proximal directions, maintaining a reference peak for instrumentation procedures. The mesial roots were mounted on a custom attachment and were pre-scanned by a micro-computed tomography system (Micro-CT; SkyScan 1174 v.2; Bruker-microCT, Kontich, Belgium) at $90-k v, 112-\mu \mathrm{A}$ and $12.8-\mu \mathrm{m}$ voxel. The images were reconstructed with NRecon Software version 1.6.9.3 (Bruker-microCT) and axial cross-sections were obtained. This initial scan provided an overview of the root canal anatomy. Only roots without canal calcification, immature apex, previous canal treatment, internal or external resorption, fracture or crack, and with only one root canal or two separate and distinct canals that were separate from the pulp chamber to the apex were included.

The root canal images and foramen images were obtained in Data Viewer software version 1.4.32 (BrukermicroCT) and the captured images were digitally processed by the software Adobe Photoshop CS3 (Adobe System Incorporated, USA). Root canal curvature was determined according to the degree (22) and radius (23) of canal curvature. To measure degree of curvature, a line was drawn parallel to the long axis of the canal. The point where the canal deviated from this line to begin canal curvature was marked as "point A". Then, a second line was drawn from the apical foramen (point B) to intersect with the "point A". The acute angle thus formed was measured (22). The line formed between points $A$ and $B$ is a chord of the hypothetical circle that defines the curved part of the canal. The curved part of the root canal between points $A$ and $B$ is the circular arc of the hypothetical circle, which is specified by its radius (23). Only root canals with curvatures between $20^{\circ}$ and $40^{\circ}$ and radius of curvature shorter than $10 \mathrm{~mm}$ were included. The foramen perimeter was also delimited. Considering the mean values of the curvatures and foramen perimeter, the roots were distributed in 4 groups $(n=10)$ by stratified randomization (www. random.org).

\section{Root Canal Treatment}

The working length (WL) was established at $1 \mathrm{~mm}$ short of the length of a size $15 \mathrm{~K}$-file (Dentsply, Maillefer) that was visible at the foramen. LA Axxess \#2 (Sybron Endo) prepared the cervical portions of all canals, which were then prepared with WOG Primary \#25.07 (Dentsply, Maillefer) up to the $W L$, using a reciprocating slow inand-out pecking motion. The apical canals patency was kept with \#15-K file. Irrigation was performed with 1\% sodium hypochlorite $(\mathrm{NaOCl})$ and, at the end, with $2 \mathrm{~mL}$ of $17 \%$ EDTA. The canals were dried and filled with AH Plus (Dentsply, Maillefer) and gutta-percha (master cone \#25.02 and accessory cones, Dentsply Maillefer) using cold lateral condensation technique.

The teeth were temporarily restored and radiographs were taken in bucco-palatal and proximal directions to confirm the filling quality. The specimens were stored in an incubator at $37^{\circ} \mathrm{C}$ and $100 \%$ humidity for 4 weeks to allow sealer setting (24).

\section{Debris Extrusion Collection and Filling Removal Procedures}

The method for debris collection was adapted from previous studies $(8,13,21)$. Briefly, Eppendorf tubes $(1,5$ $\mathrm{mL}$ ) were pre-weighted 3 times in a $10^{-5} \mathrm{~g}$ precision analytical microbalance (Sartorius AG), and the mean values were recorded. The teeth were mounted in the tubes with rubber stoppers and a 27-G needle was placed through the stoppers. The tubes were covered with black tapes to blind the operator (Fig. 1).

Irrigation was performed with distilled water and no solvent was used. LA Axxess \# 2 removed the cervical filling and the remaining material was removed according to the experimental groups, until the WL was reached. XSmart Plus (Dentsply Maillefer) was used for filling removal in WOG, PTR and DRR groups:

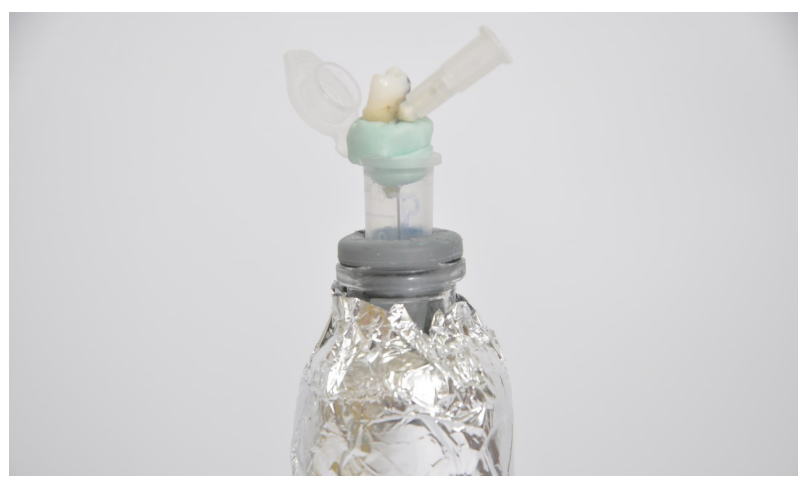

Figure 1. Apparatus used for debris extrusion collection. 
HF: K-Files \#40, \#35, \#30 and \#25 were used in circumferential, quarter turn, push-pull movement.

WOG: Primary instrument (\#25.07) was used in the "WaveOne Gold" mode of XSmart Plus.

PTR: D1 (\#30.09), D2 (\#25.08), and D3 (\#20.07) were used (600-rpm; 2-Ncm) with gentle in-and-out motion.

DRR: DR1 (\#30.10 - 1000-rpm; 1.5-Ncm) was used at the cervical and beginning of the middle thirds and DR2 (\#25.04 - 600-rpm; 1-Ncm) at the middle and apical thirds with gentle in-and-out motion.

After filling removal procedures, the Eppendorfs were removed from the vials, and the apex was washed with $1 \mathrm{~mL}$ distilled water to collect the adhered debris. The Eppendorfs were stored in an incubator at $70^{\circ} \mathrm{C}$ for 5 days, allowing water evaporation. Then, three weight measurements were taken for each collection assembly and the means were recorded. The weight of extruded debris was determined by subtracting the mean weight of the empty Eppendorf from the final mean weight of the collection assembly.

A single operator performed all endodontic procedures to avoid interoperate variability.

\section{Working time}

The time needed to complete filling removal was recorded using a digital timer (SportLine, Elmsford, USA) that was started when the first instrument was introduced into the canal and turned off when the last instrument of the sequence or the WOG instrument reached the WL.

\section{NiTi Instrument Deformation or Fracture}

All NiTi instruments were unpacked and submitted to scanning electron microscope (SEM) (JEOL, JSM 5600 LV, Tokyo, Japan) analysis. Two observers analyzed the instrument circumference and one image from the tip up to $5 \mathrm{~mm}$ at $\times 40$ magnification was recorded. Then, the instruments were numbered and re-packaged.

Each instrument used acted in 4 specimens, simulating a molar with 4 canals. As each group had 10 specimens, 2 additional filled root canals, with the same anatomical characteristics, were instrumented to complete the 4 uses for all NiTi instruments. After filling removal procedures, the instruments were cleaned by scrubbing and sonication in a biocleaner tray (Schuster, Santa Maria, RS, Brazil) containing Riozyme Il enzyme detergent (Rioquímica, São Paulo, Brazil) for $20 \mathrm{~min}$. Then, each instrument was re-analyzed by SEM, as described above. One calibrated $(I C C=0.98)$ and blinded examiner classified the images according to fracture and deformation (spiral distortion).

\section{Statistical Analysis}

Kruskal-Wallis test, followed by the Dunn's test, compared apically extruded debris between groups. One-way ANOVA, followed by Tukey's test, compared the working time data. All statistical analysis was performed on SPSS 20.0 (SPSS Inc, Chicago, IL, USA) and significance was set at $p<0.05$.

\section{Results}

\section{Debris Extrusion}

WOG extruded significantly less debris than HF and DRR $(p<0.05)$ and the other groups were not statistically different ( $p>0.05$ ) (Table 1).

\section{Working Time}

The working time for filling removal was similar for all NiTi instruments ( $>0.05)$ and higher in the HF group $(\mathrm{p}<0.05)$ (Table 2).

\section{NiTi Instrument Deformation or Fracture}

Figure 2 illustrates SEM analysis. From the three WOG instruments evaluated, one fractured and two presented distortion of two or more spirals. In PTR, the three D1 were intact, with no fracture or deformation and the three D2 presented distortion of two or more spirals. Two D3 presented distortion of two or more spirals and one fractured. From DRR, one of the three DR1 was intact, with no fracture or deformation, and two presented distortion of one spiral. One DR2 fractured and two showed distortion of one spiral.

\section{Discussion}

Several studies showed that root canal instrumentation produces apical extrusion of debris $(7,10-13,20,21,25-$

Table 1 . Median, $25^{\text {th }}$ and $75^{\text {th }}$ percentiles weight of apically extruded debris $\left(10^{-5} \mathrm{~g}\right)$

\begin{tabular}{|c|c|c|c|c|c|}
\hline Instrument & & $\mathrm{HF}$ & WOG & PTR & DRR \\
\hline Median & & $985 \mathrm{~b}$ & $770 \mathrm{a}$ & $905 a b$ & $977 \mathrm{~b}$ \\
\hline \multirow{2}{*}{ Percentiles } & 25 & 908 & 697 & 837 & 920 \\
\hline & 75 & 1044 & 891 & 1116 & 1038 \\
\hline
\end{tabular}

Values with different letters indicate statically significant difference $(\mathrm{p}<0.05)$.
Table 2. Working time with the different instruments

\begin{tabular}{ccccc}
\hline Instrument & HF & WOG & PTR & DRR \\
\hline Mean \pm SD & $2.73 \pm 1.06 \mathrm{a}$ & $111.90 \pm 33.62 \mathrm{~b}$ & $120.70 \pm 53.15 \mathrm{~b}$ & $88.29 \pm 32.84 \mathrm{~b}$ \\
\hline
\end{tabular}

Values with different letters indicate statically significant difference $(\mathrm{p}<0.05)$. 
27). However, few investigations have aimed to evaluate extruded debris during filling removal of curved canals using recent NiTi files (11). Moreover, the behavior of WOG regarding debris extrusion during filling removal is yet unknown.

As apical extrusion containing gutta-percha, sealer, organic and inorganic remnants and irrigants can lead to a negative outcome $(28,29)$, the amount of debris extruded during retreatment needs to be investigated. Therefore, the present study aimed to evaluate the apically extruded debris during filling removal of curved canals with WOG, DRR, PTR and HF.

Tanalp (14) reviewed the literature about apical extrusion and pointed out concerns regarding experimental designs used. Considering that more debris is extruded with an increase in the apical diameter (30), specimens in the present study were scanned by micro-CT, allowing delimitation of the foramen perimeters. Then, each specimen was randomly stratified in specific software for that purpose, reducing the influence of this bias.

Generally, endodontic failures are associated with treatments not properly conducted. However, complete bone healing may not occur even in a well-done endodontic treatment (1). In these cases, as simulated in the present investigation, removing the well-condensed filling material is more laborious and instrument deformation or fracture may occur. SEM analysis confirmed this assertion for all NiTi instruments tested, except for D1 (PTR) and DR1 (DRR).

The use of a solvent has been suggested to reduce the sealer microhardness, facilitating NiTi instrument insertion into filling material (31), shortening the retreatment time (32). Although the use of solvent is recommended (33), the chemically softened gutta-percha can be forced into root canal walls and into its complex anatomy that is not touched by the instruments, increasing the challenges for filling removal and possibly increasing the instrumentation time $(34,35)$. Considering these ideas and the aim to assess the performance of instruments by itself, no solvents were used herein.

In the present study, WOG extruded less debris than DRR and HF. Probably, differences in number of files and in instruments configuration, cross-section, cutting blade design, taper, tip type, alloy, flexibility, kinematics, and cutting efficacy influenced this outcome $(26,30)$. Dincer et al (10) also found more apical debris extrusion when $\mathrm{HF}$ were used in comparison with reciprocating NiTi instruments, which might be explained by differences in instruments action (9): the push-pull action performed with $\mathrm{HF}$ to advance in apical direction may have increased the risk of pumping the debris through the foramen, while
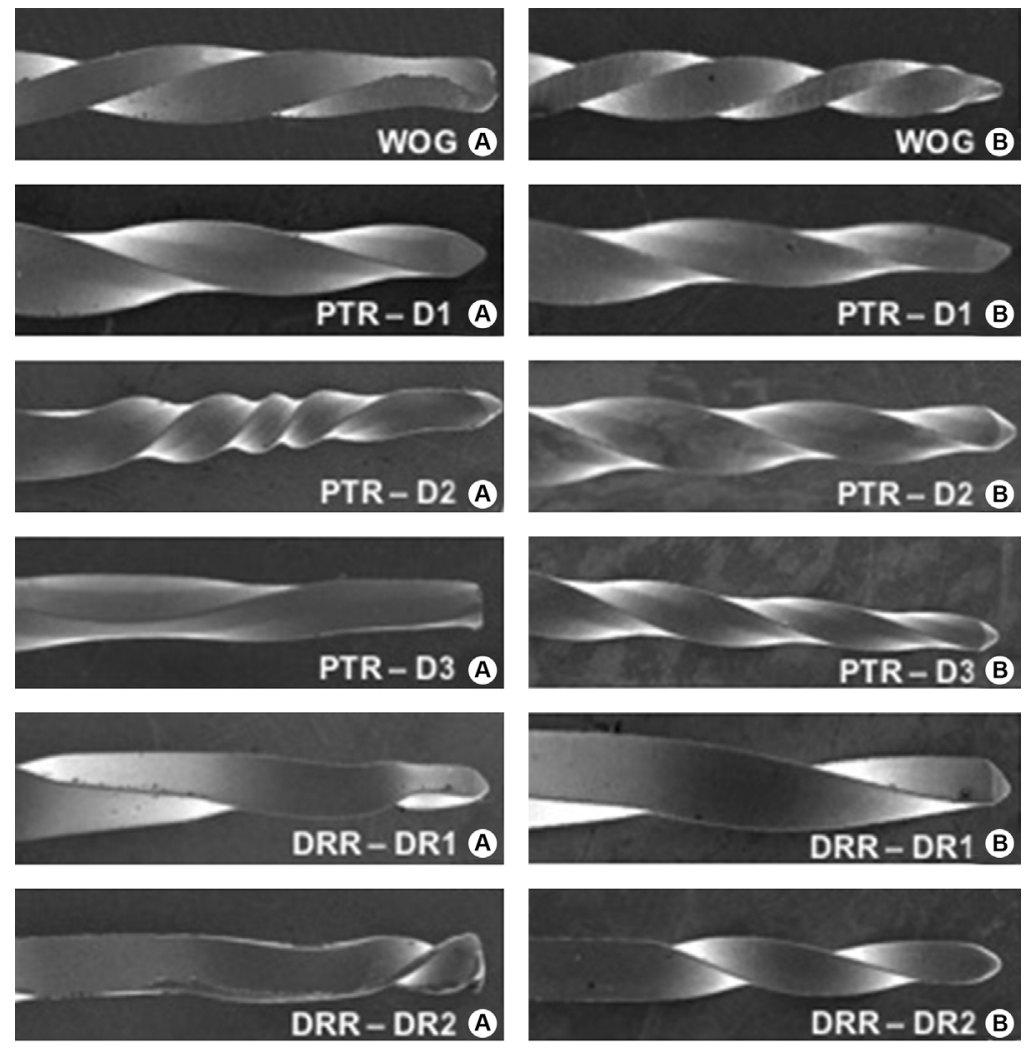

Figure 2. SEM images showing PTR (D1, D2 and D3), WOG and DRR (DR1 and DR2) instruments before (B) and after (A) instrumentation (accelerating Voltage $10.0 \mathrm{kV}$, magnification $\times 40$ ). 
the combined reciprocating motion with crown-down pressure performed with NiTi instruments could have reduced the risk of extrusion. Another possible explanation to the less extrusion of WOG could be the compaction of filling material in the apical region, as suggested by Monguilhott Crozeta et al. (36). Theoretically, the smaller the chip space of an instrument, the smaller its escape area and consequently its debris removal capacity (7). Although WOG has not been developed specifically for endodontic retreatment procedures, the present results indicate that this instrument is an alternative for root canal filling removal.

No differences were found between WOG and PTR, and between PTR and DRR. Topçuoglu et al. (9) also found no difference between PTR and DRR, and associated this fact to the similar designs in the apical third of these instruments. In contrast with the present findings, Çanakçi et al. (20), comparing a reciprocating system to rotary retreatment systems, found that the reciprocating (Reciproc) produced more debris than DRR. The authors attributed their results to differences in instruments motion. These controversial results may be explained by the differences in root canal preparation protocols. In this investigation no final - preparation was performed, aiming to assess only the $\Xi$ extruded debris caused by filling material removal. Instead, Çanakçi et al. (20) performed final root canal preparation with Reciproc \#40.06.

Regarding the working time, all NiTi systems evaluated were faster than $\mathrm{HF}$ and no differences were found between them. Similarly, Çanakçi et al. (20) reported no differences between DRR and PTR and, otherwise, Huang et al. (5) observed that the reciprocating instruments (Reciproc and WO) were faster than the rotary systems. These findings may be explained because root canal preparation with reciprocating systems requires only one instrument, while with the rotary system two or more files are necessary. These findings are controversial with the present results. Maybe the similarity in the working time of WOG and the rotary systems observed herein could be explained by WOG manufactory process, including repeated heating and cooling, which increases its flexibility. This may have hindered its penetration into the filling material, increasing the working time. Moreover, the fact that WOG has not been developed specifically for retreatment has to be considered.

Considering the limitations of in vitro investigations, caution should be taken when extrapolating the results to clinical situations (17). The collection assembly used had the apex suspended in the air without resistance. In clinical situations, the apex would be surrounded by granulomatous or periradicular tissues, which could restrict apical extrusion (37). To simulate the resistance of periapical tissue, the use of floral foam has been suggested; however, it can absorb irrigant solution and debris extruded apically while acting as a barrier (37). Considering that physical backpressure was absent in all experimental groups, this bias was controlled.

In curved root canals, all instruments evaluated caused apical debris extrusion. WOG was associated with less extrusion than DRR and HF and can be considered an alternative for filling removal during root canal retreatment. Filling removal with $\mathrm{HF}$ was slower than with the other instruments. All NiTi systems presented fracture and deformation.

\section{Acknowledgements}

The authors would like to thank Centro de Microscopia e Microanálise (CMM) of the Federal University of Rio Grande do Sul for granting permission for SEM analysis.

\section{Resumo}

0 objetivo deste estudo foi avaliar a extrusão apical de debris durante a desobturação com WaveOne Gold (WOG), ProTaper Universal Retratamento (PTR), D-RaCe (DRR) ou limas manuais (HF), comparar o tempo de trabalho durante a desobturação, e descrever as falhas dos instrumentos de NiTi. Quarenta canais de raizes mésio-vestibulares de primeiros molars superiores foram preparados com WOG Primary, obturados e divididos em 4 grupos $(n=10)$, de acordo com os instrumentos a serem utilizados: $W O G$, PTR, DRR ou HF. Água destilada foi utilizada como irrigante, e os debris extruídos foram coletados em tubos Eppendorf e secos. A quantidade de debris extruidos foi determinada subtraindo-se o peso inicial do peso final. 0 tempo de cada desobturação foi anotado e os instrumentos utilizados foram analisados no pré e pós-operatório em MEV. Os testes Kruskal-Wallis e Dunn foram utilizados para analisar os dados da extrusão de debris, e os testes ANOVA e Tukey para comparar os dados do tempo de trabalho $(\alpha=0.05)$. As deformações e fraturas dos instrumentos foram descritas. 0 grupo WOG produziu significativamente menos debris quando comparado aos grupos HFe DRR $(p<0.05)$, e foi similar ao grupo PTR ( $p>0.05)$. Os grupos HF, PTR e DRR não apresentaram diferença estatisticamente significante ( $p>0.05$ ). 0 tempo de trabalho no grupo HF foi significativamente maior do que nos outros grupos $(p<0.05)$. A análise em MEV mostrou que, dos 18 instrumentos avaliados, 3 fraturaram e em 10 foi observado deformação. Todos os sistemas testados causaram extrusão apical de debris. WOG foi associado com menor extrusão do que DRR e HF. A desobturação com $\mathrm{HF}$ foi mais lenta do que com os demais instrumentos. Todos os sistemas de NITI apresentaram fratura e deformação.

\section{References}

1. Nair PN. Pathogenesis of apical periodontitis and the causes of endodontic failures.Crit Rev Oral Biol Med 2004;15:348-381.

2. Perrini N, Castagnola L (1998). W. Hess \& O. Keller's anatomical plates: studies on the anatomical structure of root canals in human dentition by a method of making the tooth substance transparent (1928). Lainate (MI), Italy: Altini Communicazioni Grafiche.

3. Schirmeister JF, Wrbas K-T, Meyer KM, Alterburger MJ, Hellwig E. Efficacy of diferente Rotary instruments for gutta-percha removal in root canal retreatment. J Endod 2006; 469-472.

4. Bueno CE, Delboni MG, deAraújo RA, Carrara HJ, Cunha RS. Effectiveness of rotary and hand files in gutta-percha and sealer removal using chloroform or chlorhexidine gel. Braz Dent J 2006;17:139-143.5.

5. Huang $X$, Ling J, Wei $X$, et al. Quantitative evaluation of debris extruded apically by using ProTaper Universal Tulsa rotary system in endodontic retreatment. J Endod 2007;33:1102-1105.

6. Uezu MKN, Britto MLB, Nabeshima CK, Pallotta RC. Comparison of debris extruded apically and working time used by ProTaper Universal rotary and ProTaper retreatment system during gutta-percha removal. 
J Appl Oral Sci 2010;18:542-545

7. Bürklein $\mathrm{S}$, Schafer E. Apically extruded debris with reciprocating single-file and full-sequence rotary instrumentation systems. J Endod 2012;38:850-852.

8. Silva, EJ, Sá, L, Belladonna FG, Neves, AA, Accorsi-Mendonça T, Vieira VTL, De-Deus G, Moreira EJ. Reciprocating versus Rotary systems for root filling removal: assessment of the apically extruded material. J Endod 2014:40:2077-2080.

9. Topçuoglu HS, Akt A, Tunkay O, Dinçer NA, Duzgun S, Topçuoglu G. Evaluation of debris extruded apically during the removal or foot canal filling material using ProTaper, D-RaCe, and R-Endo rotary nichel-titanium retreatment instruments and hand files. J Endod 2014;40:2066-2069.

10. Dincer AN, Er O, Canakci BC. Evaluation of apically extruded debris during root canal retreatment with several NiTi systems. Int Endod J 2015;48:1194-1198.

11. Kaşıkçı Bilgi I, Köseler I, Güneri P, Hülsmann M, Çalışkan MK. Efficiency and apical extrusion of debris: a comparative ex vivo study of four retreatment techniques in reversely curved root canals. Int Endod J 2017;50:910-918.

12. Ylmaz $\mathrm{K}$ and Özyürek T. Apically extruded debris after retreatment procedure with reciproc, ProTaper Next, and Twisted File Adaptive Instruments. J Endod 2017;43:648-651.

13. Myers GL, Montgomery S. A comparison of weights of debris extruded apically by conventional filling and Canal Master techniques. J Endod 1991;17:275-279.

14. Tanalp J, Gungor T. Apical extrusion of debris: a literature review of an inherent occurrence during root canal treatment. Int Endod J 2014;47:211-221.15.

15. Ye J, Gao Y. Metallurgical characterization of M-Wire nickel-titanium shape memory alloy used for endodontic rotary instruments during low-cycle fatigue. J Endod 2012;38:105-107.

16. Gao Y, Gutmann JL, Wilkinson K, Maxwell R, Ammon D. Evaluation of the impact of raw materials on the fatigue and mechanical properties of ProFile Vortex rotary instruments. J Endod 2012;38:398-401.

17. Bürklein S, Poschmann T, Schäfer E. Shaping ability of different nickeltitanium systems in simulated S-shaped canals with and without glide path. J Endod 2014;40:1231-1234.

18. Koçak MM, Koçak S, Turker SA, Saglam BC. Cleaning efficacy of reciprocal and rotary systems in the removal of root canal filling material. J Conserv Dent 2016;19:184-188.

19. Webber J. Shaping canals with confidence: WaveOne GOLD single-file reciprocating system. Roots 2015;1:3440.

20. Çanakçi BC, Ustun Y, Er O, Sen OG. Evaluation of apically extruded debris from curved root canal filling removal using 5 Nickel-Titanium Systems. J Endod 2016;42:1101-1104.

21. Zuolo AS, Mello JE Jr, Cunha RS, et al. Efficacy of reciprocating and rotary techniques for removing filling material during root canal retreatment. Int Endod J 2013;46:947-953.
22. Schneider SW. A comparison of canal preparations in straight and curved root canals. Oral surg, Oral med, Oral pathol 1971;32:271-275.

23. Schafer E, Diez C, Hoppe W, Tepel J. Roentgenographic investigation of frequency and degree of canal curvatures in human permanent teeth. J Endod 2002;28:211-216.

24. Orstavik D, Nordahl I, Tibballs JE. Dimensional change following setting of root canal sealer materials. Dent Mater 2001; 512-519.

25. Yeter KY, Evcil MS, Ayranci LB, Ersoy I. Weight of apically extruded debris following use of two canal instrumentation techniques and two designs of irrigation needles. Int Endod J 2013;46:795-799.

26. Kirchhoff, AL, Fariniuk, LF, Mello, I. Apical extrusion of debris in flatoval root canals after using different instrumentation systems. J Endod 2015; 41:237-241.

27. Arslan H, Doganay E, Alsancak M, Çapar D, Karatas E, Gunduz HA. Comparison of apically extruded debris after root canal instrumentation using Reciproc instruments with various kinematics. Int Endod J 2016;49:307-310.

28. Siqueira J. Microbial causes of endodontic flare-ups. Int Endod J 2003;36:453-463.

29. Seltzer S, Naidorf IJ. Flare-ups in endodontics: I. Etiological factors. J Endod 2004;30:476-781.

30. Tinaz AC, Alacam T, Uzun 0, Maden M, Kayaoglu G. The effect of disruption of apical constriction on periapical extrusion. J Endod 2005;31:533-535.

31. Çanakçi BC, Er O, Dincer A. Do the sealer solvents used apically extruded debris in retreatment? J Endod 2015;41:1507-150932.

32. Giuliani V, Cocchetti R, Pagavino G. Efficacy of ProTaper Universal retreatment files in removing filling materials during root canal retreatment. J Endod 2008;34:1381-1384.

33. Tasdemir T, Yildirim T, $C_{3}$ elik D. Comparative study of removal of current endodontic fillings. J Endod 2008;34:326-329.

34. Takahashi CM, Cunha RS, De Martin AS, et al. In vitro evaluation of the effectiveness of ProTaper Universal Rotary Retreatment system for gutta-percha removal with or without a solvent. J Endod 2009;35:1580-1583.

35. Kfir A, Tsesis I, Yakirevich E, et al. The efficacy of five techniques for removing root canal filling material: microscopic versus radiographic evaluation. Int Endod J 2012;45:35-41.

36. Crozeta BM, Sousa-Neto MD, Leoni GB, Mazzi-Chaves JF, Silva-Sousa YTC, Baratto-Filho F. A micro-computed tomography assessment of the efficacy of Rotary and reciprocating techniques for filling material removal in root canal retreatment. Clin Oral Invest 2016; 20:2235-40.

37. Altundasar $E_{1}$ Nagas $E_{1}$ Uyanik 0 , Serper A. Debris and irrigant extrusion potential of 2 rotary systems and irrigation needles. Oral Surg Oral Med Oral Pathol Oral Radiol Endod 2011;112:e31-e35.

Received February 14, 2017 Accepted September 19, 2017 